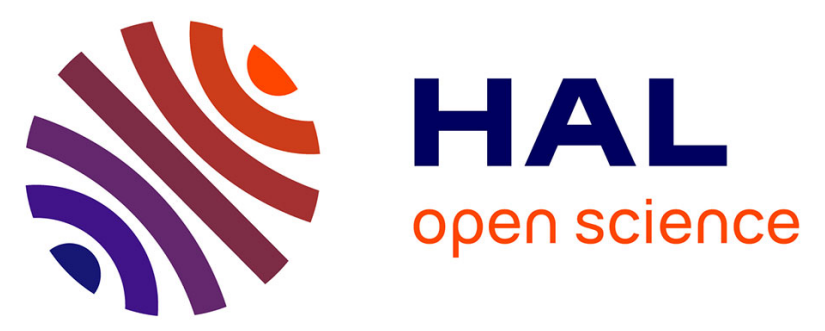

\title{
Water Flow Variability Affects Adsorption and Oxidation of Ciprofloxacin onto Hematite
}

Lian Zhou, Sebastien Martin, Wei Cheng, Laurent Lassabatère, Jean-François Boily, Khalil Hanna

\section{- To cite this version:}

Lian Zhou, Sebastien Martin, Wei Cheng, Laurent Lassabatère, Jean-François Boily, et al.. Water Flow Variability Affects Adsorption and Oxidation of Ciprofloxacin onto Hematite. Environmental Science and Technology, 2019, 53 (17), pp.10102-10109. 10.1021/acs.est.9b03214 . hal-02280838

\section{HAL Id: hal-02280838 \\ https://hal-univ-rennes1.archives-ouvertes.fr/hal-02280838}

Submitted on 2 Dec 2019

HAL is a multi-disciplinary open access archive for the deposit and dissemination of scientific research documents, whether they are published or not. The documents may come from teaching and research institutions in France or abroad, or from public or private research centers.
L'archive ouverte pluridisciplinaire HAL, est destinée au dépôt et à la diffusion de documents scientifiques de niveau recherche, publiés ou non, émanant des établissements d'enseignement et de recherche français ou étrangers, des laboratoires publics ou privés. 
Water flow variability affects adsorption and oxidation of ciprofloxacin onto hematite

Lian Zhou', Sébastien Martin ${ }^{1,2}$, Wei Cheng ${ }^{1}$, Laurent Lassabatere³, Jean-François Boily $^{2}$, Khalil Hanna ${ }^{1 *}$

${ }^{1}$ Univ Rennes, Ecole Nationale Supérieure de Chimie de Rennes, UMR CNRS 6226, 11 Allée de Beaulieu, F-35708 Rennes Cedex 7, France.

${ }^{2}$ Department of Chemistry, Umeå University, Umeå, SE-901 87, Sweden.

${ }^{3}$ Univ Lyon, Université Claude Bernard Lyon 1, CNRS, ENTPE, UMR5023 LEHNA

Vaulx-en-Velin, France.

*Corresponding author: Tel.: +33 2232380 27; fax: +33223238120.

E-mail address: khalil.hanna@ensc-rennes.fr (K. Hanna)

A revised manuscript submitted to $E S \& T$

August, 2019 


\begin{abstract}
The mobility of pharmaceuticals in environmental systems is under great scrutiny in the scientific literature and in the press. Still, very few reports have focused on redox-driven transformations when these compounds are bound to mineral surfaces, and how their transport is affected under flow-through conditions. In this study, we examined the adsorption and electron transfer reactions of ciprofloxacin (CIP) in a dynamic column containing nanosized hematite $\left(\alpha-\mathrm{Fe}_{2} \mathrm{O}_{3}\right)$. CIP binding and subsequent redox transformation were strongly dependent on inflow $\mathrm{pH}$ and residence time. These reactions could be predicted using transport models that account for adsorption and transformation kinetics. Our results show that flow interruption over a $16 \mathrm{~h}$ period triggers oxidation of hematite-bound CIP into byproducts. These reactions are likely facilitated by inner-sphere iron-CIP complexes formed via the sluggish conversion from outer-sphere complexes during interrupted flow. When intermittent flow/no-flow conditions were applied sequentially, a second byproduct was detected in the column effluent. This work sheds light on a much overseen aspect of redox transformations of antibiotics under flow-through conditions. It has important implications in adequately predicting transport, and in developing risk assessments of these emerging compounds in the environment.
\end{abstract}




\section{INTRODUCTION}

Quinolones and other antibacterial agents have emerged in the past few decades as contaminants in surface waters, groundwaters and soils. ${ }^{1,2}$ Because of their extensive uses in human and veterinary medicine, and thus their occurrence in surface water and in groundwater, the fate and behavior of antibiotics in the environment are becoming of increasing concern. ${ }^{2,3}$

Characterizing sorption and degradation processes is essential for assessing the environmental distribution, persistence, and transport of antibiotics in terrestrial and aquatic systems. These processes are strongly related to the nature and relative abundances of predominant mineral phases, such as Fe oxyhydroxide minerals of Earth's near-surface environments. $^{4,5}$ In particular, nanosized hematite $\left(\alpha-\mathrm{Fe}_{2} \mathrm{O}_{3}\right)$ is abundant in soils and sediments, ${ }^{4}$ and plays a prominent role in binding compounds, ${ }^{6-8}$ especially in clay deficient environments. Because hematite is also semi-conductor it has a strong propensity for driving heterogeneous redox reactions, namely via electron transfer between the hematite bulk and interfacially-bound antibiotic species. One electron-transfer towards the hematite bulk leads to reductive dissolution of the hematite, and oxidation of bound species, followed by the release of reaction products, such as oxidized byproducts and ferrous iron $\left(\mathrm{Fe}^{\mathrm{II}}\right) .{ }^{9-12}$ Although the redox transformation of these compounds is key to their environmental and engineered degradation, the underlying reaction mechanisms remain elusive. Additionally, little is known on how these mechanisms are influenced or coupled to water flow in saturated porous media, which is essential to translate laboratory work to field observations.

One electron-transfer reactions with Fe-oxides produce a suite of byproducts but do not sufficiently modify contaminant structure to reduce ecotoxicity or antimicrobial activity. ${ }^{13,14}$ Redox byproducts that have undergone slight structural changes (e.g. C-hydroxylation and/or $\mathrm{N}$-dealkylation) still contain biologically active moieties, and are certainly of environmental 
concern. ${ }^{15-18}$ Still, the literature is dramatically lacking comprehensive investigations of reactive transport of antibiotics and their intermediate products in metal-oxide rich systems. Such investigations are needed to understand the environmental fate and risk of antibiotics in aquatic and terrestrial environments. This becomes especially important considering the risk that antibiotics could pose in triggering the formation of bacterial resistance genes ${ }^{15-18}$ in nature.

In this work, the adsorption and redox transformation of ciprofloxacin (CIP), a representative antibiotic, ${ }^{19}$ in hematite coated sand packed columns was investigated under saturated flow conditions. Dynamic flow experiments enabled the study of nonequilibrium sorption on transport, and resolved the relationship between key hydrodynamic parameters (e.g. dispersion and advection) and solute breakthrough. In this work, flow was temporarily interrupted to test whether nonequilibrium sorption or rate-controlled processes occurred during CIP transport in columns, as previously proposed. ${ }^{20-22}$ A sequence of 'intermittent flow/no-flow' conditions were also used to mimic natural conditions where water movement through soils rarely occurs continuously. Finally, a 'flow/no-flow/flow' sequence generated data from multiple flow-interruption events, and helped describe the transport behavior under variable flow velocities.

These efforts provide evidence for important perturbations in CIP binding mechanisms and then heterogeneous oxidation reactions when water flow is altered. A transport model that accounts for adsorption and oxidation transformation kinetics predicted changes in outflow CIP concentrations and breakthrough behaviors. We explain the effect of flow variability on reaction products by the conversion kinetics of outer-sphere into inner-sphere CIP complexes which are needed to initiate heterogeneous electron transfer reactions responsible for CIP oxidation. 


\section{MATERIALS AND METHODS}

2.1. Materials. Ciprofloxacin (99\% purity) and $\mathrm{FeCl}_{3} 6 \mathrm{H}_{2} \mathrm{O}(98 \%)$ were purchased from Sigma-Aldrich and used as received. All solutions were prepared with deionized water, and the ionic strength was adjusted to $0.01 \mathrm{M}$ with $\mathrm{NaCl}$.

2.2. Preparation and characterization of solid samples. Hematite was synthesized and characterized as previously reported. ${ }^{12}$ Briefly, nanosized hematite was synthesized by forced hydrolysis of $2 \mathrm{~L}$ solutions containing $0.002 \mathrm{M} \mathrm{HCl}$ and $0.02 \mathrm{M} \mathrm{FeCl}_{3} 6 \mathrm{H}_{2} \mathrm{O}(10.8 \mathrm{~g})$ at 98 ${ }^{\circ} \mathrm{C}$. Particles were made by adding a stock solution of $\mathrm{FeCl}_{3} \cdot 6 \mathrm{H}_{2} \mathrm{O}$ to the pre-heated $0.002 \mathrm{M}$ $\mathrm{HCl}$ solution in a dropwise fashion period a $1 \mathrm{~h}$ period. The resulting solution was kept at 98 ${ }^{\circ} \mathrm{C}$ for a 4-week period. The samples were thereafter dialyzed one week with doubly distilled deionized water, during which time the dialysis water was changed on a daily basis.

Hematite was confirmed as the sole crystallographic phase in the synthetic solid by powder X-ray diffraction. Fourier Transform Infrared spectroscopy revealed no evidence of adventitious forms of $\mathrm{FeOOH}$ phases $(\alpha, \beta, \gamma)$ of low crystallinity, or of ferrihydrite. The spectra, with a broad $\mathrm{O}-\mathrm{H}$ stretching region, do however reveal the presence of nonstoichiometric hydroxyl and water molecules that are characteristic of hydrohematite, which is the prevailing form of hematite produced by the synthetic method chosen for this work. ${ }^{23}$ Transmission electron microscopy images of synthetic materials show monodisperse spherical particles with an average diameter between 80 and $90 \mathrm{~nm}$ (Fig.S1). The specific surface area, measured by multi-point $\mathrm{N}_{2}(\mathrm{~g})$ adsorption/desorption isotherm is $39.3 \mathrm{~m}^{2} / \mathrm{g}$. The point of zero charge (PZC) of hematite is 9.5 .

Hematite-coated sand (HCS) was made by coating the synthetic hematite particles with sieved quartz sand, following the method of Scheiddeger et al. ${ }^{24}$ Briefly, the purified Fontainebleau quartz sand was mixed with hematite suspension for $24 \mathrm{~h}$ at room temperature. 
The coated sand was thereafter washed with deionized water to remove salts, then centrifuged and dried under a $\mathrm{N}_{2}(\mathrm{~g})$ atmosphere. ${ }^{19}$ All synthetic solids were washed to remove soluble $\mathrm{Fe}$ and electrolytes, and stored at ambient temperature. The hematite content deposited on the sand surface, measured by acid digestion analysis, was $1.10 \mathrm{~g}$ per $100 \mathrm{~g}$ sand.

2.3. Dynamic flow column breakthrough experiments. Column experiments were conducted at room temperature. Dry HCS (15 g) was packed into glass column having internal diameter of $1.6 \mathrm{~cm}$ providing bed length of $4.7 \mathrm{~cm}$. After packing to a uniform bulk density $\left(1.59 \pm 0.05 \mathrm{~g} / \mathrm{cm}^{3}\right)$, the column was wetted against gravity with a $0.01 \mathrm{M} \mathrm{NaCl}$ solution at a constant flow rate. Once the column was water saturated, the flow characteristics of the porous bed were determined by a non-reactive tracer experiment. Keeping the flow rate constant, a pulse of $5 \mathrm{~mL}$ of a $10^{-2} \mathrm{M}$ potassium bromide $(\mathrm{KBr})$ solution ( $\mathrm{pH} \sim 6$ ) was injected. A $\mathrm{Br}^{-}$breakthrough curve was obtained by collecting effluent and then analyzing with ionic chromatography. The hydrodynamic parameters were then determined using classical Advection Dispersion Equation (ADE):

$$
\frac{\partial C}{\partial t}=D \frac{\partial^{2} C}{\partial x^{2}}-v \frac{\partial C}{\partial x}
$$

where $C$ is the water solute concentration $\left(\mathrm{M} / \mathrm{L}^{3}\right), t$ denotes time $(\mathrm{T}), x$ is the spatial coordinate $(\mathrm{L}), D$ represents the dispersion coefficient $\left(\mathrm{L}^{2} / \mathrm{T}\right)$, and $v$ is the velocity $=\mathrm{q} / \theta(\mathrm{L} / \mathrm{T})$ with $\mathrm{q}$ is the Darcy flux $(\mathrm{L} / \mathrm{T}), \theta$ is the volumetric water content $\left(\mathrm{L}^{3} / \mathrm{L}^{3}\right)$.

Breakthrough curves (BTC) for $\mathrm{Br}^{-}$at two flow rates $(0.1$ and $1 \mathrm{~mL} / \mathrm{min})$ were symmetrically shaped with no significant tailing (Fig.S2), thus confirming the absence of considerable dispersion/diffusion or physical nonequilibrium effects. Macroscopic dispersivity ( $1.89 \mathrm{~mm}$ ), obtained by the ratio of the dispersion coefficient (D) and of pore velocity (v), was larger than the sand particle size $(200-300 \mu \mathrm{m})$. Molecular diffusion was considered negligible with respect to the dynamic dispersion. The Péclet number $(\mathrm{Pe}=\mathrm{vL} / \mathrm{D})$ 
was $\sim 30$ in the column, indicating that advection dominated transport, and the flow can be assumed to be homogeneous. During water saturation and tracer experiments, total Fe in outflow was below detection limit (i.e. $0.2 \mu \mathrm{M}$ ), and therefore possibility of dissolution and/or dispersion of hematite particles was excluded from the column.

The column was then injected with CIP solution in two types of input boundary condition: (1) step injection at constant flow rate and (2) continuous mode with one or more periods of flow-interruption. For the step-type boundary condition, four sets of column experiments were performed with a step injection of $20 \mu \mathrm{M}$ CIP solution at different inflow $\mathrm{pH}$ ( $\mathrm{pH} 5.5$ and 7) and two flow rates ( 1 and $0.1 \mathrm{~mL} / \mathrm{min}$ ) or residence times (3.7 $\mathrm{min}$ and $37 \mathrm{~min}$, respectively). The influent solution was adjusted to desired $\mathrm{pH}$ with $\mathrm{HCl}$ or $\mathrm{NaOH}$ solutions, and purged with $\mathrm{N}_{2(\mathrm{~g})}$ throughout the course of the experiment. The $\mathrm{pH}$ of effluent was monitored by an on-line $\mathrm{pH}$ detector, and also checked by a $\mathrm{pH}$ meter with a resolution of 0.001 . A lower flow rate $(0.1 \mathrm{~mL} / \mathrm{min})$ was used to increase column residence time $(37 \mathrm{~min})$ to study nonequilibrium sorption. For the flow-interruption boundary condition, two sets of column experiments were initiated with a steady application of CIP solution at two flow rates (1 and $0.1 \mathrm{~mL} / \mathrm{min}$ ) until the effluent of CIP concentration reached a steady-state value, at which time the flow was stopped. After a flow-interruption period of $16 \mathrm{~h}$, a steady flow of an influent CIP solution was resumed at lower flow rate $(0.1 \mathrm{~mL} / \mathrm{min})$. By repeating flow-no flow-flow sequence, another set of column experiment with multiple flow-interruption events was performed at high flow rate $(1 \mathrm{~mL} / \mathrm{min})$. Experimental conditions for the column breakthrough experiments are summarized in Table $\mathrm{S} 1$. To ensure $\mathrm{O}_{2}$-free conditions, all inflow solutions used for saturation, tracer and reactive experiments were purged with $\mathrm{N}_{2}(\mathrm{~g})$, and the influent cap flask was maintained under a $\mathrm{N}_{2}$ pressure barrier to avoid $\mathrm{O}_{2}$ or $\mathrm{CO}_{2}$ contamination throughout the course of the experiment. Oxide-free control batch tests showed no decay of CIP in all experimental conditions investigated here. Additional control tests 
performed in presence of hematite showed very comparable rate constants under oxic vs anoxic conditions, excluding the $\mathrm{O}_{2}$ contribution in the removal reaction.

The column was wrapped with aluminum foil to eliminate the possibility of a photoassisted reaction. After experiment, the column was transferred to anaerobic chamber in glove box. The solid was transferred to $0.1 \mathrm{M} \mathrm{NaOH}$ and shaken for $1 \mathrm{~h}$. Then the supernatants were filtered $(0.2 \mu \mathrm{m})$ and CIP and byproducts were measured by LC-MS.

CIP concentrations were determined by a high performance liquid chromatography (HPLC) system with an auto sampler (Waters 717 plus), using a C18 column (250 mm×4.6 mm i.d., $5 \mu \mathrm{m}$ ) and a UV detector operating at $275 \mathrm{~nm}$ (Waters 2489). The mobile phase was a mixture of water/acetonitrile $(75: 25 \mathrm{v} / \mathrm{v})$ containing $0.1 \%$ of formic acid. The flow rate of the mobile phase was set at $1 \mathrm{~mL} / \mathrm{min}$ in isocratic mode. The by-products were, in turn, analyzed with a Waters ultra HPLC-MS (Acquity UPLC) system using a Waters BEH C18 column $(100 \mathrm{~mm} \times 2.1 \mathrm{~mm}, 1.7 \mu \mathrm{m})$ and a mass spectrometer. The mobile phase consisted of acetonitrile containing $0.1 \%$ of formic acid (eluant A) and mixture acetonitrile/water $10 \% / 90 \%$ containing $0.1 \%$ of formic acid (eluant B) with gradient 0 min/0\% $\mathrm{A}-1 \mathrm{~min} / 0 \% \mathrm{~A}$ - $9 \mathrm{~min} / 100 \% \mathrm{~A}-12 \mathrm{~min} / 0 \% \mathrm{~A}$, and a flow rate of $400 \mu \mathrm{L} / \mathrm{min}$. An electrospray interface (ESI) was used for the MS measurements in positive ionisation mode and full scan acquisition. Finally, dissolved ferrous ion was determined by uv-visible spectrophotometry (Cary 50 probe, Varian) using the 1-10 phenanthroline method. ${ }^{25}$

2.4. Modeling solute transport. The mathematical model used in this study is based on a two-site, advective-dispersive transport model with degradation and Freundlich-Langmuir kinetic sorption. The liquid and sorbed concentrations are ruled by the following differential equation that governs the chemical non-equilibrium transport for a homogeneous system under steady-state water flow: ${ }^{26}$ 


$$
\theta \frac{\partial C}{\partial t}+\rho \frac{\partial S}{\partial t}=\theta D \frac{\partial^{2} C}{\partial x^{2}}-q \frac{\partial C}{\partial x}-\mu_{\mathrm{l}} \theta C-\mu_{\mathrm{s}} \rho S
$$

where $\theta$ is the volumetric water content $\left(\mathrm{L}^{3} / \mathrm{L}^{3}\right), C$ is the volume-averaged solution concentration $\left(\mathrm{M} / \mathrm{L}^{3}\right), t$ is time $(\mathrm{T}), \rho$ is soil bulk density, $S$ is the sorbed concentration $(\mathrm{M} / \mathrm{M})$, $\mathrm{D}$ is the dispersion coefficient in the liquid phase $\left(\mathrm{L}^{2} / \mathrm{T}\right), q$ is the volumetric flux density (L/T), $\mu_{1}$ and $\mu_{\mathrm{s}}$ are first-order degradation rate constants $\left(\mathrm{T}^{-1}\right)$ for the liquid and sorbed phases.

Our two-site sorption model considers instantaneous (type-1 sites; $S^{\mathrm{e}}$ ), and kinetic (type-2 sites; $\left.S^{\mathrm{k}}\right)^{26}$ sorption sites contributing to the sorbed concentration, $S$ :

$$
S=S^{\mathrm{e}}+S^{\mathrm{k}}
$$

The instantaneous site term is expressed with ${ }^{26}$

$$
S^{\mathrm{e}}=f K_{\mathrm{d}} \frac{C^{\beta}}{1+\eta C^{\beta}}
$$

where here $f$ is the fraction of instantaneous sorption sites, $\mathrm{K}_{\mathrm{d}}, \beta$ and $\eta$ are empirical coefficients. The kinetic term is expressed with: ${ }^{26}$

$$
\frac{\partial S^{\mathrm{k}}}{\partial t}=\omega\left[(1-f) K_{\mathrm{d}} \frac{C^{\beta}}{1+\eta C^{\beta}}-S^{\mathrm{k}}\right]-\mu_{\mathrm{s}} S^{\mathrm{k}}
$$

where $\omega$ is the first-order kinetics rate $\left(\mathrm{T}^{-1}\right)$.

Transport modeling was performed with HYDRUS 1D. ${ }^{27}$ This code allows for the numerical resolution of equations 2-5 for several boundary and initial conditions: concentration flux at the inlet, zero concentration gradient at the outlet, and no solute at time zero. By using a least-squares optimization routine, HYDRUS 1D also allows inverse modeling to fit the model solution to the data to estimate fate and transport parameters. ${ }^{28}$ Considering that previous batch data ${ }^{12}$ indicates that sorption was kinetically limited, we presumed that all the sorption sites are kinetically controlled $\left(f_{\mathrm{k}}=0\right)$. In addition, by presuming that CIP transformation reactions only occurred at the hematite surface, $\mu_{1}$ was set 
to 0 . This also allows to reduce the number of estimated parameters, and thus avoid nonuniqueness issues. Values for the sorption parameters $\left(K_{\mathrm{d}}, \beta\right.$ and $\left.\eta\right)$, kinetics parameter $\omega$ and the first-order degradation rate $\mu_{\mathrm{s}}$ were determined through fitting the breakthrough curves of CIP. At high flow rate (i.e. $1 \mathrm{~mL} / \mathrm{min}$ ), the first-order degradation rate $\mu_{\mathrm{s}}$ was set to 0 since no oxidation was expected under those conditions. A complete sensitivity analysis including the modeling approach used in the present work is presented in the supporting information (Text S1). 


\section{RESULTS AND DISCUSSION}

\subsection{CIP breakthrough at two $\mathrm{pH}$ values and two flow rates}

Breakthrough experiments of CIP were conducted at two different inflow $\mathrm{pH}\left(\mathrm{pH}_{\mathrm{in}}\right)$ and two flow rates $(0.1$ and $1 \mathrm{~mL} / \mathrm{min})$ (Fig. 1$)$. Outflow $\mathrm{pH}$ increased only very slightly (less than $0.4 \mathrm{pH}$ unit) at both water velocities, then regained the original $\mathrm{pH}_{\text {in }}$ value when solute breakthrough achieved steady state. A dependence of BTC shapes on the flow rate points to possibilities of kinetic limitations in the system. A high velocity $(1 \mathrm{~mL} / \mathrm{min})$ produced an early breakthrough and achieving a $\mathrm{C} / \mathrm{C}_{0}$ ratio of 1 , while the $\mathrm{BTC}$ at the lower flow rate $(0.1$ $\mathrm{mL} / \mathrm{min}$ ) does not attain 1 . For instance, at $\mathrm{pH}_{\text {in }} 5.5$, the breakthrough point for CIP starts at $\sim 15 \mathrm{PV}$ at $1 \mathrm{~mL} / \mathrm{min}$ and is completed at $\sim 45 \mathrm{PV}$, while at $0.1 \mathrm{~mL} / \mathrm{min}$ the solute breaks out at around $22 \mathrm{PV}$ (Fig.1) and then achieves a steady state breakthrough at around $\mathrm{C} / \mathrm{C}_{0} \sim 0.9$.

CIP exists in the cationic, zwitterionic and anionic forms ( $\mathrm{pK}_{\mathrm{a}} 5.46$ and 7.67). CIP binding at hematite surfaces is expected to be similar at $\mathrm{pH} 5.5$ and 7 where hematite surfaces are positively charged and CIP was dominated by zwitterionic species (Fig.S3). Accordingly, we observed slightly more sorption at $\mathrm{pH} 5.5\left(0.19\right.$ molecule $\left./ \mathrm{nm}^{2}\right)$ than at $\mathrm{pH} 7(0.12$ molecule $/ \mathrm{nm}^{2}$ ) in HCS-packed column. This result is comparable to our previously published adsorption results under comparable conditions ${ }^{12}\left(20 \mu \mathrm{M}\right.$ CIP on $39.3 \mathrm{~m}^{2} / \mathrm{L}$ of hematite at $0.01 \mathrm{M}$ of $\mathrm{NaCl}$ ), to a kinetic study investigated at two $\mathrm{pH}$ values (See text $\mathrm{S} 2$ ), and previous report. $^{29}$

Vibrational spectroscopic and chromatographic work ${ }^{12}$ show that CIP predominantly binds to hematite as bidentate complexes, i.e. involving one oxygen atom of the carboxylic group and one oxygen atom of the carbonyl group. Binding is then followed by an heterogeneous electron transfer process resulting in the concomitant oxidation of CIP and reduction of surface-bound iron. No CIP oxidation occurred at least within the first hour of equilibration under batch conditions, a period which is longer than the residence time of CIP 
$(0.6 \mathrm{~h})$ in the column for the lowest flow rate. However, the breakthrough behavior suggests that both adsorption and transformation processes may occur in the HCS column, particularly at the low flow rate where complete breakthrough (i.e. $\left.\mathrm{C} / \mathrm{C}_{0}=1\right)$ is never attained.
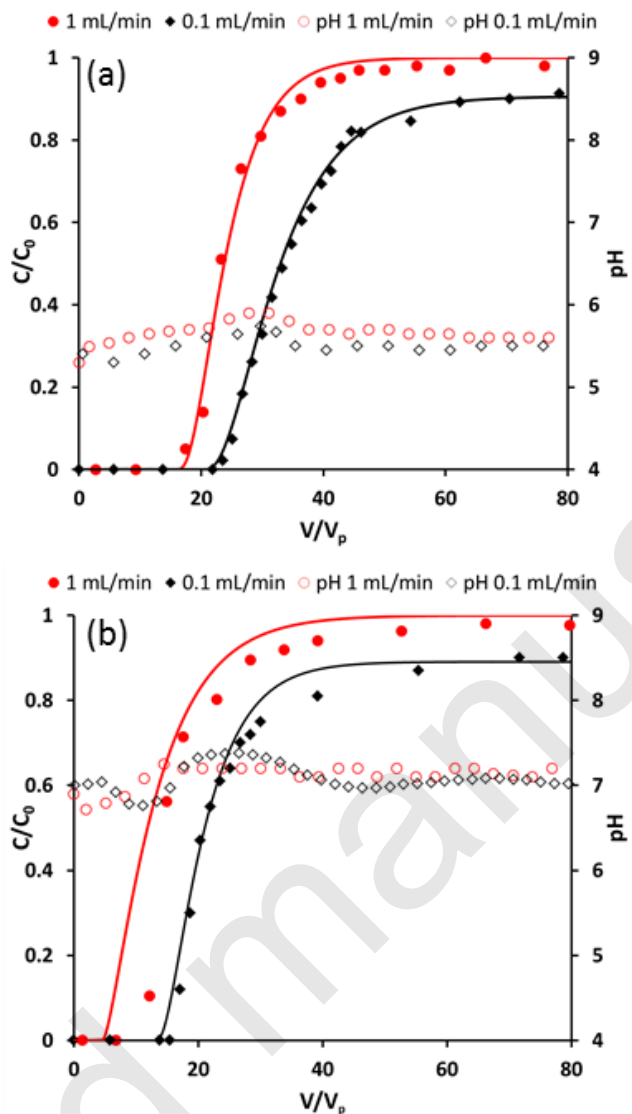

Fig.1 Experimental and modeling BTCs of CIP at two flow rates. Inflow conditions: $20 \mu \mathrm{M}$ CIP; $10 \mathrm{mM}$ $\mathrm{NaCl}$; PV=3.7 mL, inflow pH 5.5 (a) and 7 (b). Solid lines represent the calculated BTC.

Hydrus-1D modeling results of the BTC using sorption parameters of Table 1 shows that the empirical distribution coefficient $K_{\mathrm{d}}$ at $0.1 \mathrm{~mL} / \mathrm{min}$ is larger than in $1 \mathrm{~mL} / \mathrm{min}$, whereas $\beta$ values are relatively close. At low flow rate, CIP oxidation at hematite surfaces is expected ${ }^{12}$ and thus concomitant release of oxidation byproducts and ferrous iron from surfaces may occur. Incorporation of first-order degradation rate constants, $\mu_{\mathrm{s}}\left(\mathrm{min}^{-1}\right)$, is required to account for the partial breakthrough at low flow rate. As the both calculated and experimental BTCs point to adsorption and CIP oxidation mechanisms in the column, the additional set of 
experiments aimed at assessing further oxidation reactions was focused at $\mathrm{pH} 5.5$, where CIP/hematite interactions are most favorable.

\subsection{Impact of water flow variability on CIP oxidation in column}

In a first step, flow-interruption experiments were conducted at two different flow rates, 1 $\mathrm{mL} / \mathrm{min}(\mathrm{Col}-5)$ and $0.1 \mathrm{~mL} / \mathrm{min}(\mathrm{Col}-6)$. After the flow-interruption period, the flow was resumed at $0.1 \mathrm{~mL} / \mathrm{min}$ in both column experiments. A $16 \mathrm{~h}$ flow interruption period (Fig.2) allowed for solutions and newly formed surface species to react over a longer period during flow-through conditions. Resuming the flow shows a depletion of BTC in those solutions at both flow rates, although this breakthrough front seems to be dependent on flow rate. An independent set of flow interruption experiments, using $\mathrm{Br}^{-}$as a non-reactive compound (Fig.S4), showed no drop in the $\mathrm{Br}^{-}$BTC. The aforementioned changed in CIP concentrations can therefore not be caused by the presence of immobile water content or physical nonequilibrium (i.e., diffusive mass transfer between "mobile" and "immobile" regions). ${ }^{21,22}$

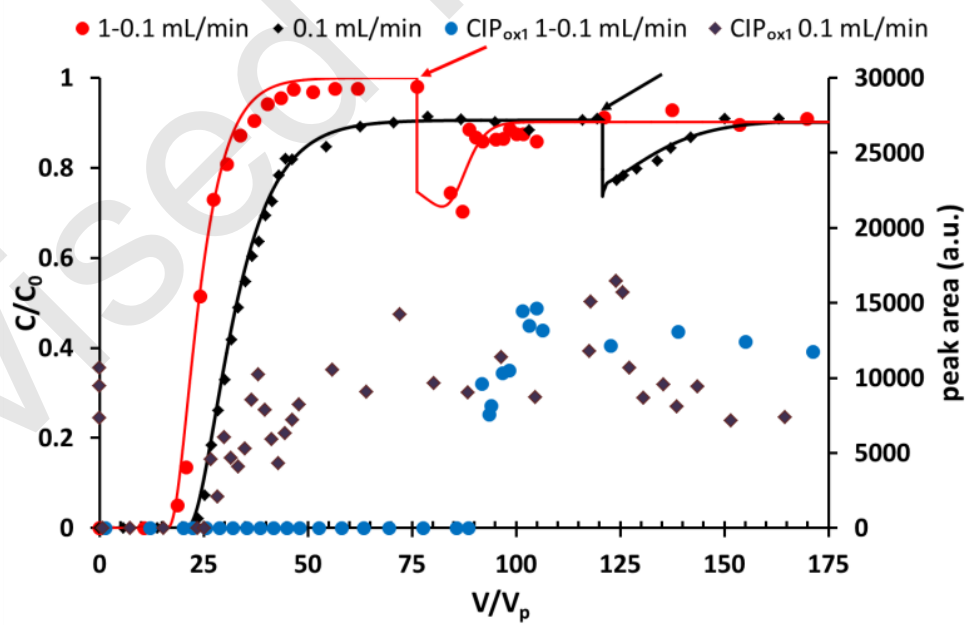

Fig.2 Experimental and calculated BTCs of CIP at two flow rates $(0.1$ and $1 \mathrm{~mL} / \mathrm{min})$. Inflow conditions: $\mathrm{pH}_{\mathrm{in}}$ 5.5; $20 \mu \mathrm{M}$ CIP; $10 \mathrm{mM} \mathrm{NaCl} ; \mathrm{PV}=3.7 \mathrm{~mL}$. After the flow-interruption period, the flow was resumed at 0.1 $\mathrm{mL} / \mathrm{min}$. $\mathrm{CIP}_{\mathrm{ox} 1}(\mathrm{M}-26)$ is the primary CIP byproduct and only detected by LC-MS. Solid lines represent the calculated BTC. The arrow indicates the moment of flow-interruption (duration 16h). 
The loss of CIP in solutions reacted under no-flow condition can be explained by cooccurring adsorption reactions and heterogeneous redox reactions that are kinetically limited. In order to assess the oxidation reaction, all possible byproducts previously detected ${ }^{12-13}$ were searched by LC/MS. A predominant species of mass-to-charge ratio of $\mathrm{m} / \mathrm{z}=306\left(\mathrm{CIP}_{\mathrm{ox}}, \mathrm{M}\right.$ 26) was of noteworthy interest (Fig.S5). The peak areas of the LC/MS data of these species were comparable for both flow rates, yet differ in the breakthrough point (rise up). Indeed, this byproduct breaks out only after the no-flow period (interruption) at high flow rate, while at lower flow rate $(0.1 \mathrm{~mL} / \mathrm{min})$ it follows CIP breakthrough to reach a steady state (Fig.2). In the former case, the byproduct breakthrough was observed irrespective of the resumed flow rate (i.e. $0.1 \mathrm{~mL} / \mathrm{min}$ in Fig. 2 or $1 \mathrm{~mL} / \mathrm{min}$ in Fig.S6). It is worth noting that electron transfer between the organic compound and $\mathrm{Fe}(\mathrm{III})$ generates $\mathrm{Fe}(\mathrm{II})$, which is likely to be rapidly adsorbed onto hematite. Fe(II) adsorption by hematite can occur at $\mathrm{pH}$ values as low as $4 . .^{30,31}$ Adsorption can then be followed by interfacial electron transfer with structural $\mathrm{Fe}(\mathrm{III})$ of hematite. ${ }^{32}$ Recently, Frierdich et al. ${ }^{33}$ showed that structural Fe(III) atoms exchanged with $\mathrm{Fe}(\mathrm{II})$ in solution but this process remains very slow ( $>30$ days). This would explain the absence of detectable ferrous iron (detection limit $0.2 \mu \mathrm{M}$ ) in the column effluent. We note that low amounts of hematite $(\sim 1 \mathrm{wt} \%)$ in HCS hinder our ability to directly assess possible modifications in hematite. However, it is important to monitor the speciation of iron and/or organic compounds contacted to mineral surfaces in the column system to better understand specific mechanisms of the reactions, which warrants future research.

Rates of chemical reactions caused by flow interruption can be experimentally estimated using CIP concentrations of the column effluent immediately before $\left(C_{b}\right)$ and after $\left(C_{a}\right)$ the flow-interruption event through: ${ }^{34}$ 


$$
k=-\frac{\ln \left(\frac{C_{a}}{C_{b}}\right)}{t_{i}}
$$

where $t_{i}$ is the duration of flow interruption and $k\left(\mathrm{~min}^{-1}\right)$ is the first-order rate coefficient (Table S2). The latter parameter represents all reactions (i.e. adsorption and oxidation reactions) that can cause concentration decay during the flow-interruption period.

On the other hand, the first-order degradation rate $\mu_{\mathrm{s}}$ values can be fitted using Hydrus-1D software at $0.1 \mathrm{~mL} / \mathrm{min}$, where the oxidation reaction takes place and reaction byproducts are detected (Table 2). The transport and sorption parameters were kept constant for the three steps (flow/no-flow/flow), except the degradation rate coefficient. The optimized $\mu_{\mathrm{s}}$ values were highly comparable to the coefficient $k$ estimated with Eqn. 6, suggesting that the concentration drop during the flow-interruption period could be mainly ascribed to the oxidation reaction and that adsorption is of lesser extent. Furthermore, numerical results show that the $\mu_{\mathrm{s}}$ value remained unchanged in the col-6 when the same flow rate was applied before and after the stop-flow period.

\subsection{Formation of oxidation byproducts under multiple stop-flow events}

A flow/no-flow/flow sequence was repeated to generate data from multiple flowinterruption events (called Col-7) at high flow rate (1 mL/min) (Fig.3). Comparison between the influent and effluent CIP concentration suggests significant changes in rate and extent of reactions (i.e. adsorption and degradation), which may occur during the flow-interruption periods. 


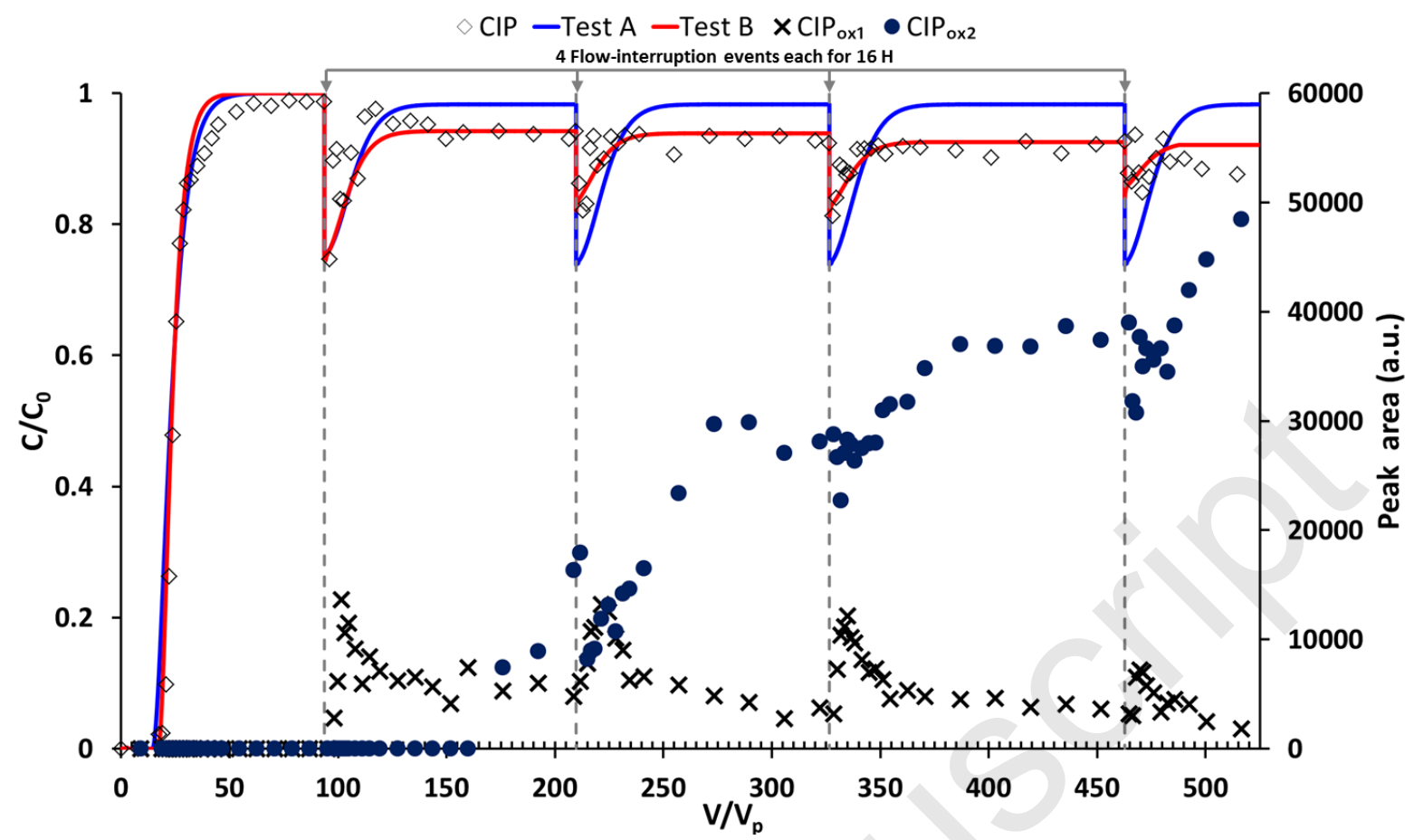

Fig.3 BTCs of CIP and two primary by-products $\left(\mathrm{CIP}_{\text {ox } 1}(\mathrm{~m} / \mathrm{z} 306)\right.$ and $\left.\mathrm{CIP}_{\text {ox } 2}(\mathrm{~m} / \mathrm{z} 263)\right)$ under multiple stop flow events. Inflow conditions: flow rate $1 \mathrm{~mL} / \mathrm{min} ; \mathrm{pH}_{\text {in }} 5.5 ; 20 \mu \mathrm{M}$ CIP; $10 \mathrm{mM} \mathrm{NaCl} ; \mathrm{PV}=3.7 \mathrm{~mL}$.

After each flow interruption period, where both sorption/desorption and oxidation reactions are expected, CIP concentrations decreased and byproduct concentrations increased, and then approached constant steady-state values. No significant change (less than $0.1 \mathrm{pH}$ units) in $\mathrm{pH}$ was observed for each interruption event (not shown). In addition to the primary byproduct $(\mathrm{m} / \mathrm{z}=306)$ detected in columns 5 and 6 , a second byproduct was detected by LC/MS corresponding to $\mathrm{m} / \mathrm{z}=263$ with concentrations continuously increasing during transport. Solid extraction on the HCS after termination of the experiment confirmed the coexistence of CIP and its two byproducts. This suggests that the oxidation and formation of CIP byproducts occurs from the first stop-flow event, and continues to take place in the column, even at high flow rate $(1 \mathrm{~mL} / \mathrm{min})$, since complete breakthrough (i.e. $\left.\mathrm{C} / \mathrm{C}_{0}=1\right)$ is never attained. 
Spectroscopic and chromatographic analyses ${ }^{12}$ showed that CIP can be oxidized by hematite through a one electron transfer from the $\mathrm{N}$ atom of piperazine ring to surface- $\mathrm{Fe}^{3+}$, generating a surface-bound $\mathrm{Fe}^{\mathrm{II}}$ and $\mathrm{CIP}$ cation radical. The formed radicals can then undergo further changes through $\mathrm{C}$-hydroxylation and/or N-dealkylation, causing ring opening and subsequent formation of two byproducts corresponding to $\mathrm{m} / \mathrm{z}=306(\mathrm{M}-26)\left(\mathrm{CIP}_{\mathrm{ox} 1}\right)$ and $\mathrm{m} / \mathrm{z}$ $=263(\mathrm{M}-69)\left(\mathrm{CIP}_{\mathrm{ox} 2}\right)$ through the chain reaction:

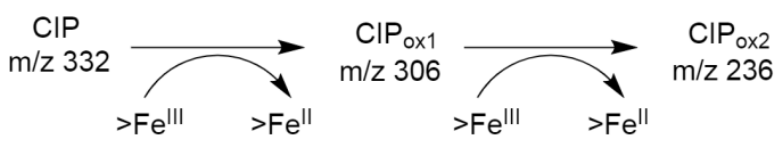

Intermediate steps in the oxidation reaction may influence the sorption dynamics and then the breakthrough behavior. Once generated and released from the surface, the primary byproduct will re-bind to hematite surfaces. This is indicated by the sequent formation of $\operatorname{CIP}_{\text {ox2 }}(\mathrm{m} / \mathrm{z} 263)$ through interaction of $\mathrm{CIP}_{\text {ox } 1}(\mathrm{~m} / \mathrm{z} 306)$ with hematite surfaces.

Two BTCs of CIP were then calculated using Hydrus-1D with different degradation rate coefficients ( $c f$. tests A and B in Fig.3). The sorption and transport parameters derived from simulation data of Col-1 (the same flow rate, $1 \mathrm{~mL} / \mathrm{min}$ ) were used. Before the first no-flow step, the first-order degradation rate $\mu_{\mathrm{s}}$ was set to 0 in both modeling tests $\mathrm{A}$ and $\mathrm{B}$. After the flow-interruption was performed, $\mu_{\mathrm{s}}$ was set to a constant value of $1.7 \times 10^{-4} \mathrm{~min}^{-1}$ in the test $\mathrm{A}$. In contrast, different values of $\mu_{\mathrm{s}}$ were obtained by fitting the experimental data of test $\mathrm{B}$ (Table 3) as it improves the description of changes in CIP concentrations both after resuming flow and at the plateau of CIP breakthrough after the first no flow step (FI-1). As displayed in the BTC (Fig.3) and further confirmed by modeling parameters (Table 3), the most significant change in transport behavior was observed after the first interruption event. Afterwards, partial breakthrough of CIP develops into a flat plateau over the subsequent three events. 
It is also worth noting that the calculated degradation rate constants of CIP over the course of the flow/no-flow/flow sequence is consistent with the rate coefficient values obtained by Eq. 6 (Table S2), thereby underscoring once again the predominant contribution of degradation over the adsorption reaction. Additionally, the computed $\mu_{\mathrm{s}}$ values are in agreement with the initial oxidation rate constants estimated from batch kinetic study (See Text S2 and Figure S2-1). As in the previous sets of column experiments, dissolved ferrous iron concentration was below detection limit $(0.2 \mu \mathrm{M})$ in the effluent column, and this can be explained if ferrous iron is rapidly readsorbed onto hematite. ${ }^{32,33}$ It is worth noting that the $\mathrm{Fe}(\mathrm{II})$ amount releasable to account for CIP oxidation assuming 1:1 stoichiometry represents a very small percentage of total Fe loaded into the column $(<0.005 \%)$.

\section{ENVIRONMENTAL IMPLICATIONS}

Water migration through the porous networks of soils takes place often, if not always, discontinuously or at least through large fluctuations in flow velocities. Periods where flow is halted while chemical reactions continue to progress frequently occur in nature, yet these events tend to be overlooked in column studies. In the present work, we have examined for the first time how 'intermittent flow/no-flow/flow' conditions affected the sorption/redox reaction of antibiotics, byproducts formation and their reactive transport. We also varied the water velocity before and after the flow-interruption period to mimic natural flow variability conditions. Heterogeneous oxidation reactions releasing byproducts were triggered during interrupted flow, and continued to take place whatever the resumed flow rate, while the oxidation reaction was absent at high flow rate before the flow interruption. Multiple stopflow events can even facilitate the formation of a second type of byproduct that would otherwise remain unseen under constant flow experiments. These results can be explained if heterogeneous oxidation reactions require iron-bonded CIP complexes that facilitate direct 
inner-sphere electron transfer. ${ }^{35,36}$ In contrast, physisorbed or hydrogen-bonded CIP are less susceptible to one-electron oxidation reactions, and would require more time to convert to metal-bonded species. These conversion kinetics fall in line with an earlier spectroscopic study $^{37}$ tracking a sluggish conversion of hydrogen-bonded organic species to metal-bonded complexes. We also developed a new transport model that accounts for adsorption and transformation kinetics to predict changes in outflow concentrations and breakthrough behaviors.

This work sheds light on a much overseen aspect of redox transformations of antibiotics under flow-through conditions, and has strong implications in adequately predicting their redox-active transport in environments subject to variable water velocities. Models accounting for these phenomena are crucial to our understanding of the transport and mobility of emerging contaminants in terrestrial and aquatic environments.

The main problem related with the presence of antibiotics and their intermediate products in environmental systems is the possibility of inducing bacterial resistance genes. ${ }^{15-18}$ Failure to take into consideration redox mechanisms coupled to water flow in natural porous media may introduce a bias in the characterization of affected environments leading to misevaluation of ecotoxicity. Therefore, predicting mobility of parents and daughter compounds in groundwater and subsurface environments is crucial for assessing potential genotoxic effects and human health risks.

\section{SUPPORTING INFORMATION}

TEM image of hematite; experimental and calculated BTCs of non-reactive tracer (bromide); chemical speciation of CIP versus $\mathrm{pH}$ and identified oxidation byproducts; experimental and calculated BTCs of CIP where the flow rate was kept constant before and after flow interruption; experimental conditions for dynamic column breakthrough experiments; 
degradation rate coefficients calculated from multiple flow-interruption events using eq. 6 . Modeling approach including sensitivity analysis and associated figures. Batch kinetic study of $\mathrm{CIP} /$ hematite interactions at two $\mathrm{pH}$ values.

\section{ACKNOWLEDGMENTS}

This work was supported by Rennes Metropole (K.H) and by the Swedish Research Council (2016-03808 to J.-F.B.) We gratefully acknowledge the Chinese Scholarship Council of PR China for providing financial support for Lian Zhou to stay at the ENSCR. 


\section{REFERENCES}

(1) Kümmerer, K. Antibiotics in the Aquatic Environment - A Review - Part I. $\begin{array}{llll}\text { Chemosphere } & \mathbf{2 0 0 9}, & 75 & \text { 417-434. }\end{array}$ https://doi.org/10.1016/j.chemosphere.2008.11.086.

(2) Jia, A.; Wan, Y.; Xiao, Y.; Hu, J. Occurrence and Fate of Quinolone and Fluoroquinolone Antibiotics in a Municipal Sewage Treatment Plant. Water Research 2012, 46 (2), 387-394. https://doi.org/10.1016/j.watres.2011.10.055.

(3) Zhang, T.; Li, B. Occurrence, Transformation, and Fate of Antibiotics in Municipal Wastewater Treatment Plants. Critical Reviews in Environmental Science and Technology 2011, 41 (11), 951-998. https://doi.org/10.1080/10643380903392692.

(4) Cornell, R. M.; Schwertmann, U. The Iron Oxides Structure, Properties, Reactions, Occurences and Uses; Wiley-VCH: Weinheim; Cambridge, 2003.

(5) Hochella, M. F.; Lower, S. K.; Maurice, P. A.; Penn, R. L.; Sahai, N.; Sparks, D. L.; Twining, B. S. Nanominerals, Mineral Nanoparticles, and Earth Systems. Science 2008, 319 (5870), 1631-1635. https://doi.org/10.1126/science.1141134.

(6) Marsac, R.; Martin, S.; Boily, J.-F.; Hanna, K. Oxolinic Acid Binding at Goethite and Akaganéite Surfaces: Experimental Study and Modeling. Environ. Sci. Technol. 2016, 50 (2), 660-668. https://doi.org/10.1021/acs.est.5b04940.

(7) Gu, C.; Karthikeyan, K. G. Sorption of the Antimicrobial Ciprofloxacin To Aluminum and Iron Hydrous Oxides. Environ. Sci. Technol. 2005, 39 (23), 9166-9173. https://doi.org/10.1021/es051109f.

(8) Paul, T.; Liu, J.; Machesky, M. L.; Strathmann, T. J. Adsorption of Zwitterionic Fluoroquinolone Antibacterials to Goethite: A Charge Distribution-Multisite Complexation Model. Journal of Colloid and Interface Science 2014, 428, 63-72. https://doi.org/10.1016/j.jcis.2014.04.034. 
(9) Kung, K.-H.; McBride, M. B. Electron Transfer Processes Between Hydroquinone and Iron Oxides. Clays Clay Miner. 1988, $36 \quad$ (4), 303-309. https://doi.org/10.1346/CCMN.1988.0360403.

(10) Yanina, S. V.; Rosso, K. M. Linked Reactivity at Mineral-Water Interfaces through Bulk Crystal Conduction. Science 2008, $320 \quad$ (5873), 218-222. https://doi.org/10.1126/science.1154833.

(11) Hanna, K.; Quilès, F. Surface Complexation of 2,5-Dihydroxybenzoic Acid (Gentisic Acid) at the Nanosized Hematite-Water Interface: An ATR-FTIR Study and Modeling Approach. Langmuir 2011, 27 (6), 2492-2500. https://doi.org/10.1021/la104239x.

(12) Martin, S.; Shchukarev, A.; Hanna, K.; Boily, J.-F. Kinetics and Mechanisms of Ciprofloxacin Oxidation on Hematite Surfaces. Environ. Sci. Technol. 2015, 49 (20), 12197-12205. https://doi.org/10.1021/acs.est.5b02851.

(13) Zhang, H.; Huang, C.-H. Adsorption and Oxidation of Fluoroquinolone Antibacterial Agents and Structurally Related Amines with Goethite. Chemosphere 2007, 66 (8), 1502-1512. https://doi.org/10.1016/j.chemosphere.2006.08.024.

(14) Feitosa-Felizzola, J.; Hanna, K.; Chiron, S. Adsorption and Transformation of Selected Human-Used Macrolide Antibacterial Agents with Iron(III) and Manganese(IV) Oxides. Environmental Pollution $\quad$ 2009, $157 \quad$ (4), $1317-1322$. https://doi.org/10.1016/j.envpol.2008.11.048.

(15) Besse, J.-P.; Kausch-Barreto, C.; Garric, J. Exposure Assessment of Pharmaceuticals and Their Metabolites in the Aquatic Environment: Application to the French Situation and Preliminary Prioritization. Human and Ecological Risk Assessment: An International Journal 2008, 14 (4), 665-695. https://doi.org/10.1080/10807030802235078.

(16) Zampakou, M.; Akrivou, M.; Andreadou, E. G.; Raptopoulou, C. P.; Psycharis, V.; Pantazaki, A. A.; Psomas, G. Structure, Antimicrobial Activity, DNA- and Albumin- 
Binding of Manganese(II) Complexes with the Quinolone Antimicrobial Agents Oxolinic Acid and Enrofloxacin. Journal of Inorganic Biochemistry 2013, 121, 88-99. https://doi.org/10.1016/j.jinorgbio.2012.12.013.

(17) Michael, I.; Vasquez, M. I.; Hapeshi, E.; Haddad, T.; Baginska, E.; Kümmerer, K.; Fatta-Kassinos, D. Metabolites and Transformation Products of Pharmaceuticals in the Aquatic Environment as Contaminants of Emerging Concern. In Transformation Products of Emerging Contaminants in the Environment; Lambropoulou, D. A., Nollet, L. M. L., Eds.; John Wiley and Sons Ltd: Chichester, United Kingdom, 2014; pp 413458. https://doi.org/10.1002/9781118339558.ch14.

(18) Cuprys, A.; Pulicharla, R.; Brar, S. K.; Drogui, P.; Verma, M.; Surampalli, R. Y. Fluoroquinolones Metal Complexation and Its Environmental Impacts. Coordination Chemistry Reviews 2018, 376, 46-61. https://doi.org/10.1016/j.ccr.2018.05.019.

(19) Golet, E. M.; Alder, A. C.; Hartmann, A.; Ternes, T. A.; Giger, W. Trace Determination of Fluoroquinolone Antibacterial Agents in Urban Wastewater by Solid-Phase Extraction and Liquid Chromatography with Fluorescence Detection. Anal. Chem. 2001, 73 (15), 3632-3638. https://doi.org/10.1021/ac0015265.

(20) Murali, V.; Aylmore, L. a. G. No-Flow Equilibration and Adsorption Dynamics during Ionic Transport in Soils. Nature 1980, $283 \quad$ (5746), 467. https://doi.org/10.1038/283467a0.

(21) Brusseau, M. L.; Rao, P. S. C.; Jessup, R. E.; Davidson, J. M. Flow Interruption: A Method for Investigating Sorption Nonequilibrium. Journal of Contaminant Hydrology 1989, 4 (3), 223-240. https://doi.org/10.1016/0169-7722(89)90010-7.

(22) Brusseau, M. L.; Hu, Q.; Srivastava, R. Using Flow Interruption to Identify Factors Causing Nonideal Contaminant Transport. Journal of Contaminant Hydrology 1997, 24 (3), 205-219. https://doi.org/10.1016/S0169-7722(96)00009-5. 
(23) Boily, J.-F.; Yeşilbaş, M.; Md. Musleh Uddin, M.; Baiqing, L.; Trushkina, Y.; SalazarAlvarez, G. Thin Water Films at Multifaceted Hematite Particle Surfaces. Langmuir 2015, 31 (48), 13127-13137. https://doi.org/10.1021/acs.langmuir.5b03167.

(24) Scheidegger, A.; Borkovec, M.; Sticher, H. Coating of Silica Sand with Goethite: Preparation and Analytical Identification. Geoderma 1993, 58 (1), 43-65. https://doi.org/10.1016/0016-7061(93)90084-X.

(25) Tamura, H.; Goto, K.; Yotsuyanagi, T.; Nagayama, M. Spectrophotometric Determination of Iron(II) with 1,10-Phenanthroline in the Presence of Large Amounts of Iron(III). Talanta 1974, 21 (4), 314-318. https://doi.org/10.1016/0039-9140(74)80012-3.

(26) van Genuchten, M. Th.; Wagenet, R. J. Two-Site/Two-Region Models for Pesticide Transport and Degradation: Theoretical Development and Analytical Solutions. Soil Science Society of America Journal 1989, $53 \quad$ (5), 1303. https://doi.org/10.2136/sssaj1989.03615995005300050001x.

(27) Šimůnek, J.; van Genuchten, M. T. Modeling Nonequilibrium Flow and Transport Processes Using HYDRUS. Vadose Zone Journal 2008, 7 (2), 782-797. https://doi.org/10.2136/vzj2007.0074.

(28) Casey, F. X. M.; Larsen, G. L.; Hakk, H.; Šimůnek, J. Fate and Transport of 17ßEstradiol in Soil-Water Systems. Environ. Sci. Technol. 2003, 37 (11), 2400-2409. https://doi.org/10.1021/es026153z.

(29) Gu, X.; Tan, Y.; Tong, F.; Gu, C. Surface Complexation Modeling of Coadsorption of Antibiotic Ciprofloxacin and $\mathrm{Cu}(\mathrm{II})$ and onto Goethite Surfaces. Chemical Engineering Journal 2015, 269, 113-120. https://doi.org/10.1016/j.cej.2014.12.114.

(30) Jeon, B.-H.; Dempsey, B. A.; Burgos, W. D.; Royer, R. A. Reactions of Ferrous Iron with Hematite. Colloids and Surfaces A: Physicochemical and Engineering Aspects 2001, 191 (1-2), 41-55. https://doi.org/10.1016/S0927-7757(01)00762-2. 
(31) Jeon, B.-H.; Dempsey, B. A.; Burgos, W. D. Kinetics and Mechanisms for Reactions of Fe(II) with Iron(III) Oxides. Environ. Sci. Technol. 2003, 37 (15), 3309-3315. https://doi.org/10.1021/es025900p.

(32) Larese-Casanova, P.; Scherer, M. M. Fe(II) Sorption on Hematite: New Insights Based on Spectroscopic Measurements. Environ. Sci. Technol. 2007, 41 (2), 471-477. https://doi.org/10.1021/es0617035.

(33) Frierdich, A. J.; Helgeson, M.; Liu, C.; Wang, C.; Rosso, K. M.; Scherer, M. M. Iron Atom Exchange between Hematite and Aqueous Fe(II). Environ. Sci. Technol. 2015, 49 (14), 8479-8486. https://doi.org/10.1021/acs.est.5b01276.

(34) Das, B. S.; Lee, L. S.; Rao, P. S. C.; Hultgren, R. P. Sorption and Degradation of Steroid Hormones in Soils during Transport: Column Studies and Model Evaluation. Environ. Sci. Technol. 2004, 38 (5), 1460-1470. https://doi.org/10.1021/es034898e.

(35) McBride, M. B. Adsorption and Oxidation of Phenolic Compounds by Iron and Manganese Oxides 1. Soil Science Society of America Journal 1987, 51 (6), 1466-1472. https://doi.org/10.2136/sssaj1987.03615995005100060012x.

(36) Rosokha, S. V.; Kochi, J. K. Fresh Look at Electron-Transfer Mechanisms via the Donor/Acceptor Bindings in the Critical Encounter Complex. Acc. Chem. Res. 2008, 41 (5), 641-653. https://doi.org/10.1021/ar700256a.

(37) Axe, K.; Persson, P. Time-Dependent Surface Speciation of Oxalate at the WaterBoehmite $(\gamma-\mathrm{AlOOH})$ Interface: Implications for Dissolution. Geochimica et Cosmochimica Acta 2001, 65 (24), 4481-4492. https://doi.org/10.1016/S00167037(01)00750-5. 
Table 1. Parameters of CIP transport under step-injection condition

\begin{tabular}{|c|c|c|c|c|}
\hline Column ID & Col-1 & Col-2 & Col-3 & Col-4 \\
\hline Flow rate $(\mathrm{mL} / \mathrm{min})$ & 1 & 0.1 & 1 & 0.1 \\
\hline Inflow $\mathrm{pH}$ & 5.5 & 5.5 & 7 & 7 \\
\hline$f(\%)$ & 0 & 0 & 0 & 0 \\
\hline $\mathrm{K}_{\mathrm{d}}\left(\mathrm{mol}^{1-\beta} \mathrm{L}^{\beta} \mathrm{g}^{-1}\right)$ & $5.8 \times 10^{-3}$ & $7.8 \times 10^{-3}$ & $3.1 \times 10^{-3}$ & $4.9 \times 10^{-3}$ \\
\hline$\beta(-)$ & 0.40 & 0.40 & 0.25 & 0.30 \\
\hline$\eta(-)$ & 0 & 0 & 0 & 0 \\
\hline$\Omega\left(\min ^{-1}\right)$ & $9.5 \times 10^{-2}$ & $5.9 \times 10^{-3}$ & $7.1 \times 10^{-2}$ & $6.8 \times 10^{-3}$ \\
\hline$\mu_{\mathrm{s}}\left(\min ^{-1}\right)$ & 0 & $8.0 \times 10^{-5}$ & 0 & $1.5 \times 10^{-4}$ \\
\hline $\mathrm{R}^{2}$ & 0.9942 & 0.9985 & 0.9849 & 0.9935 \\
\hline
\end{tabular}


Table 2. Parameters of CIP transport under flow-interruption conditions

\begin{tabular}{ccccccc}
\hline Column ID & \multicolumn{3}{c}{ Col-5 } & \multicolumn{3}{c}{ Col-6 } \\
Flow rate (mL/min) & 1 & 0 & 0.1 & 0.1 & 0 & 0.1 \\
$f(\%)$ & 0 & 0 & 0 & 0 & 0 & 0 \\
$\mathrm{~K}_{\mathrm{d}\left(\mathrm{mol}^{1-\beta} \mathrm{L}^{\beta} \mathrm{g}^{-1}\right)}$ & $5.8 \times 10^{-3}$ & $5.8 \times 10^{-3}$ & $5.8 \times 10^{-3}$ & $7.8 \times 10^{-3}$ & $7.8 \times 10^{-3}$ & $7.8 \times 10^{-3}$ \\
$\beta(-)$ & 0.40 & 0.40 & 0.40 & 0.40 & 0.40 & 0.40 \\
$\eta(-)$ & 0 & 0 & 0 & 0 & 0 & 0 \\
$\Omega\left(\mathrm{min}^{-1}\right)$ & $9.5 \times 10^{-2}$ & $9.5 \times 10^{-2}$ & $9.5 \times 10^{-2}$ & $5.9 \times 10^{-3}$ & $5.9 \times 10^{-3}$ & $5.9 \times 10^{-3}$ \\
$\mu_{\mathrm{s}}\left(\mathrm{min}^{-1}\right)$ & 0 & $1.7 \times 10^{-4}$ & $1.1 \times 10^{-4}$ & $8.0 \times 10^{-5}$ & $8.0 \times 10^{-5}$ & $8.0 \times 10^{-5}$ \\
\hline
\end{tabular}


Table 3. Degradation rate coefficient $\left(\mathrm{min}^{-1}\right)$ estimated from curve-fitting by using Hydrus-1D (Test B in Fig.3).

\begin{tabular}{ccccc}
\hline Flow-interruption event & FI-1 & FI-2 & FI-3 & FI-4 \\
$\mu_{\mathrm{s}}\left(\mathrm{min}^{-1}\right)$ & $1.7 \times 10^{-4}$ & $7.3 \times 10^{-5}$ & $7.6 \times 10^{-5}$ & $4.6 \times 10^{-5}$ \\
Recommencing-Flow & RF-1 & RF-2 & RF-3 & RF-4 \\
$\mu_{\mathrm{s}}\left(\mathrm{min}^{-1}\right)$ & $6.5 \times 10^{-4}$ & $6.9 \times 10^{-4}$ & $8.4 \times 10^{-4}$ & $8.5 \times 10^{-4}$ \\
\hline
\end{tabular}




\section{Graphical Abstract}

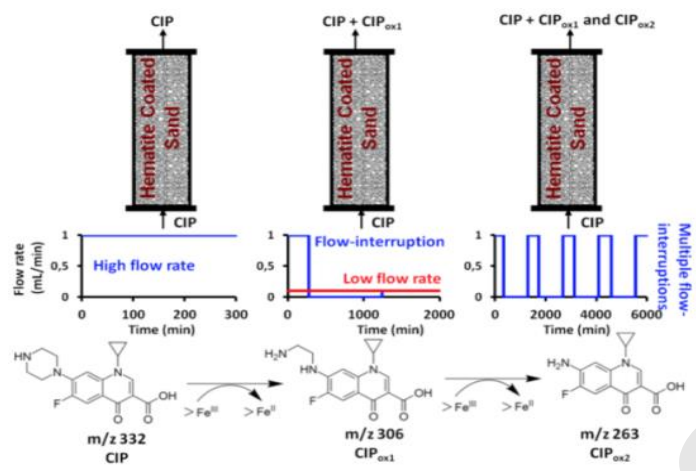

